SEÇÃO TEMÁTICA: ADOLESCÊNCIA NA CIDADE: QUESTÕES PARA OS CAMPOS DA PSICANÁLISE, EDUCAÇÃO E POLÍTICA

\title{
Os Cortes na Adolescência e a Busca por um Lugar na Cidade
}

\author{
Luciana Coutinho' \\ Bruna Madureira'
}

'Universidade Federal Fluminense (UFF), Niterói/RJ - Brasil

RESUMO - Os Cortes na Adolescência e a Busca por um Lugar na Cidade. Diante do alto índice de atos autolesivos em adolescentes no Brasil e no mundo, pretende-se analisar o apelo recorrente a esse recurso na adolescência, discutindo questões relativas ao laço social nele implicadas. Tal discussão será feita a partir do caso clínico de uma adolescente de 14 anos, encaminhado pela escola para o SPIA/IPUB-UFRJ e marcado pela presença da angústia e do desamparo, cujas possibilidades de inscrição psíquica e endereçamento parecem vacilar. $\mathrm{O}$ artigo é fruto de pesquisa em andamento sobre autolesões e suicídio na adolescência, que pretende contribuir para a construção de dispositivos, particularmente nos âmbitos da saúde e da educação, para intervir e manejar esse problema clínico-político de nossos tempos.

Palavras-chave: Adolescente. Atos Autolesivos. Desamparo. Educação.

ABSTRACT - Cutting in Adolescence and the Search for a Place in the City. Given the high rate of self-injury among adolescents in Brazil and worldwide, this paper intends to analyze this resource's recurrent use in adolescence, discussing issues related to the social bond implied in it. This discussion is based on the clinical case of a 14-year-old adolescent referred by her school to SPIA/IPUB-UFRJ. The youngster showed apparent anguish and helplessness, whose possibilities of psychic inscription and addressing seem to falter. The article results from ongoing research on self-injury and suicide in adolescence, which aims to contribute to developing strategies, particularly in the fields of health and education, to intervene and manage this clinical-political problem of our times.

Keywords: Adolescent. Self-cutting. Helplessness. Education.

Educação \& Realidade, Porto Alegre, v. 46, n. 1, e109167, 2021. 
Os Cortes na Adolescência e a Busca por um Lugar na Cidade

Quando digito a primeira palavra, o sangue ainda mancha os dentes da boca do meu braço. Das bocas todas do meu braço. Depois da primeira palavra não me corto mais. Eu agora sou ficção. Como ficção eu posso existir (Eliane Brum, 2011, p. 01)

\section{Introdução}

Nos últimos anos, temos tido notícias bastante alarmantes sobre a recorrência de diversas práticas de autolesão entre jovens no Brasil e no mundo ${ }^{1}$. Constata-se que as práticas da autolesão, bem como as tentativas de suicídio, ocupam um espaço cada vez maior nas pautas da saúde pública, particularmente no âmbito da escola e entre os jovens. Dentre as práticas autolesivas, o cortar-se parece ter se tornado um recurso comum na adolescência para lidar com as dificuldades inerentes ao movimento de deslocamento do universo infantil em direção à busca por um lugar de inserção nos discursos sociais e na cidade, o que implica sempre em alguma quota de angústia e desamparo.

Com efeito, os rituais de passagem, que, nas sociedades tradicionais, ofereciam um caminho mais seguro para a inserção na polis, se diluíram, provocando um sentimento de desamparo e solidão que marcam a adolescência desde seu nascimento, na Modernidade ${ }^{2}$. Na adolescência contemporânea, isso se intensifica, diante de em um cenário social destituído de suportes simbólicos e institucionais legítimos e composto por uma família que vem perdendo o seu lugar de amparo e referência diante da aceleração trazida pela sociedade de consumo e pela tecnologia. Soma-se a isso a hegemonia do discurso científico aliada aos avanços do neoliberalismo no Brasil e no mundo, que produz efeitos no lugar ocupado por instâncias públicas que agenciem mecanismos coletivos de proteção social. Toma parte nesse mal-estar, que se agrava diante da condição de vulnerabilidade social em que se encontram muitos jovens e suas famílias no contexto de desigualdade social brasileiro, a precariedade dos investimentos do estado no âmbito da educação nos últimos anos e a perda de legitimidade das instituições educativas.

Frente ao cenário acima descrito, a pesquisa ${ }^{3}$ acerca da autolesão na adolescência é relevante, na medida em que nos possibilita refletir sobre este ato como uma das respostas encontradas pelos adolescentes nos dias atuais para lidar com a sua dor de existir (Lacan, 1998b), uma dor que é inerente ao estar vivo, mas que parece ser potencializada em tempos de rupturas e esgarçamentos do tecido social. No artigo exploramos, portanto, questões associadas à travessia a ser feita pelo sujeito adolescente, tais como a ressignificação das relações familiares e a abertura maior para o social, conduzindo o adolescente a um reposicionamento subjetivo frente à alteridade. A elaboração da falta no Outro, na tensão entre alienação e separação, é reeditada em outras esferas da vida, quando o adolescente busca, na cultura, outras referências para o seu desejo. Por isso, como apontou Freud, em 1910 (Freud, 1970[1910]), as instituições educativas estão necessariamente implicadas na construção de novos laços com a vida e no desejo de viver na adolescência. 
Dito isso, nosso objetivo é pensar sobre os atos de autolesão em adolescentes na contemporaneidade que parecem se constituir para alguns como uma das únicas saídas possíveis para lidar com o mal-estar que os assola na travessia da adolescência. Frequentemente, escutamos na clínica com adolescentes que os cortes servem para aliviar a dor psíquica que está para além do que se consegue suportar, sendo a sensação física aparentemente o único recurso que possuem para dar um contorno ao transbordamento pulsional ao qual ficam submetidos. Tais questões serão exploradas através da apresentação do caso clínico de uma adolescente de 17 anos atendida no Serviço de Psiquiatria da Infância e da Adolescência (SPIA) do IPUB/UFRJ durante os anos de 2018 e 2019.

Como referencial metodológico, baseamo-nos no paradigma da pesquisa em psicanálise, pautada pelos princípios éticos que norteiam a sua clínica (Alberti; Elia, 2008), levando em conta o desejo do analista na construção da questão de pesquisa e na escrita do caso, tanto quanto o laço transferencial com o analista/pesquisador na produção do material a ser analisado (Poli, 2008). Assim, retomando Lacan (1990 [1964], p. 14), ao citar Picasso quando diz “[...] eu não procuro, eu acho”, a prática de pesquisa em psicanálise produz o sujeito e não apenas o descobre. É nesse sentido que, na psicanálise, não se pesquisa para comprovar uma verdade, mas sim para dar testemunho de um encontro com o real de cada caso ou cada situação estudada. Sem deixar de marcar a presença desse real também na singularidade da escrita do caso feita por aquele que o conduziu (Iribarry, 2003).

Para isso, serão utilizados registros escritos dos atendimentos clínicos feitos pela pesquisadora/psicóloga responsável pelos atendimentos da paciente em questão, mediante autorização da adolescente e seus responsáveis ${ }^{4}$. A partir da apresentação de extratos do caso, podemos supor que, frente a uma impossibilidade de pensar e elaborar o excesso pulsional que lhes invade nesse momento lógico da constituição subjetiva, muitos adolescentes ficam imersos no desamparo, cujo efeito é uma angústia inenarrável. Pretendemos discutir também a dimensão sociopolítica desse sofrimento, pensada a partir dos impasses na inscrição psíquica da alteridade, que se articulam à forte incidência do discurso capitalista neoliberal na escola e na cidade de maneira ampla, o que compromete o trabalho de novos enlaçamentos sociais e a construção de um discurso em nome próprio na adolescência.

\section{Adolescência, Desamparo e Alteridade}

A adolescência é um momento crucial na constituição do sujeito, com implicações particulares no que diz respeito à inscrição no laço social. Implica em um trabalho psíquico de (re)conhecimento do corpo, ressignificação das relações familiares, abertura para o social, aumento das possibilidades de ser e de estar na cidade. Tudo isso impõe ao adolescente um reposicionamento em relação à alteridade (Santos; Salada, 2013). Para a psicanálise, a adolescência é um percurso de elaboração de escolhas, que inclui, sobretudo, o trabalho de elaboração da falta no Outro, encarnado na infância em seus pais ou cuidadores, e posterior- 
Os Cortes na Adolescência e a Busca por um Lugar na Cidade

mente, no Outro localizado no campo social mais amplo. Deparar-se com o fato da incompletude do Outro é, para o adolescente, muito difícil, pois implica em um trabalho de luto, na medida que precisa lidar com o fato de que o Outro não tem respostas para as suas perguntas. Em outras palavras, que o Outro é faltoso.

Embora a adolescência não seja um conceito originalmente estudado pela psicanálise, Freud (1972) não faz diferença entre adolescência e puberdade. Para o psicanalista, a puberdade engloba as transformações psíquicas e corporais. Sublinha que o trabalho psíquico mais importante da puberdade é o desligamento da autoridade paterna, imprescindível para a evolução cultural e que, ao mesmo tempo, reflete a crise da adolescência. Se a infância se constitui como um tempo de grande idealização dos pais, a adolescência, ao contrário, é justamente o momento de desidealização das figuras onipotentes infantis.

Entretanto, a presença dos pais é fundamental para que o adolescente possa escolher lançar mão deles ou não. Então, para desidealizar os pais, é preciso que estes estejam presentes na vida dos filhos. E se os pais estão ausentes, ao adolescente não é oferecida a possibilidade da escolha. Por vezes, os pais desistem de desempenhar a sua função, em virtude das inúmeras reações adversas - violentas e agressivas - de seus filhos. Quando os pais optam por se separar dos filhos antes mesmo destes se separarem deles, invertendo-se os papéis, a única solução encontrada pelo adolescente, que se vê abandonado pelos pais, é lutar com todas as forças pela atenção destes (Alberti, 2004).

\section{[...] é porque os pais estão lá que o adolescente pode es- colher lançar mão deles ou não; quer dizer, se os pais não estão presentes ele não poderá sequer fazer essa escolha. E a adolescência é, antes de mais nada: 1) um longo traba- lho de elaboração de escolhas e 2) um longo trabalho de elaboração da falta no Outro (Alberti, 2004, p. 10).}

Se, por um lado, o adolescente busca desesperadamente o olhar dos pais, estes, muitas vezes, sentem dificuldade em sustentar a adolescência dos seus filhos. É preciso construir a capacidade de investir amorosamente em seus filhos para que estes possam investir neles próprios. Para isso, é fundamental que os pais possam suportar o seu próprio aniquilamento para poder cuidar dos filhos adolescentes. Somente desta maneira seus filhos poderão escolher - isso sim, aquilo não. Embora nem sempre todas as referências dos pais sirvam para os filhos, o fato de tê-las já é de grande valia para o adolescente (Alberti, 2004). Se os pais ocupam uma posição desejante no laço ao Outro, isso pode ser transmitido aos seus filhos, que passam a desejar o mesmo ou o diferente a partir do desejo de seus pais. Por isso, a referência anterior é tão importante. Nesse sentido, o Outro preexiste ao sujeito com a finalidade de engendrá-lo, e a referência à alteridade é justamente aquilo que possibilita a construção de um eu diferenciado.

A adolescência sempre é, de alguma forma, um trabalho solitário e acompanhado de uma experiência de desamparo. Frente às falhas parentais, é preciso, agora, se separar do Outro - sinônimo dos pais 
idealizados e imaginarizados -, entretanto, esse processo de separação só terá êxito se, anteriormente, os pais tiverem sido incorporados pelo adolescente. Com efeito, quanto mais sólida for a incorporação dos pais, mais recurso psíquico o sujeito adolescente terá para tomar as suas próprias decisões (Alberti, 2004). Se, para a criança, o peso da relação parental se presentifica como demanda de amor e busca pela garantia de proteção contra o desamparo, agora tudo isso se abala. $\mathrm{O}$ adolescente percebe que não há como escapar do desamparo fundamental, que subjaz intrínseco ao ser humano. A constatação de que o Outro não pode protegê-lo é dolorosa. O adolescente demite o Outro da sua função salvadora (Lacan, 1999). Como encarar o desamparo sem as referências ao Outro da infância? Como criar recursos frente ao inevitável da castração?

Para se autorizar a desejar, é essencial reconhecer a castração do Outro e de si própria, já que o desejo se alimenta justamente da falta. Na medida em que os pais são castrados (se mostram castrados), os filhos carregam, em si, esta bagagem para seguirem sozinhos o seu próprio desejo. Portanto, poder encarar de frente o desamparo é submeter-se à castração - lei da vida. Somente reconhecendo as próprias impossibilidades e limites é que se faz possível um trabalho de elaboração da falta no Outro. Este é o processo da adolescência. Processo cujo resultado é encontrar no Outro do inconsciente as suas heranças que lhe servirão de sustentação ao longo da sua vida.

Muitas vezes, o adolescente se isola frente ao desligamento gradativo da autoridade dos pais, em virtude de mal-entendidos familiares. Apesar de, muitas vezes, não apresentar recursos para enfrentar as dificuldades e hostilidades que a vida apresenta, o adolescente agora busca agir em nome próprio. $\mathrm{O}$ ato, que requer autoria e autoridade, corresponde a fazer uma escolha e implica em uma responsabilidade. $\mathrm{O}$ atravessamento da adolescência corresponde à recusa em satisfazer a demanda do Outro para se assumir a si próprio como sujeito do desejo. Mas é a presença do Outro barrado que permite o investimento do sujeito para além do seu meio familiar. É deste modo que a lei do desejo operante na família permite que a experiência de um outro lugar se instaure para a criança e para o adolescente (Julien, 2000; Zelmanovich, 2014), onde a escola e os laços sociais extrafamiliares podem incidir.

Na adolescência, particularmente, a escola ocupará um lugar de destaque (Freud, 1970[1910]; 1996[1914]). Como já trabalhamos anteriormente, diante do declínio dos ideais da infância, a escola é o lugar de encontro com outros adultos, outros discursos e outros ideais, também através das trocas com os pares (Coutinho, 2015; 2019). Por isso, ela não deixa de estar implicada na travessia adolescente e na construção de novos enlaçamentos discursivos. A respeito disso, o olhar e o investimento que o Outro escolar tem sobre o adolescente terá impacto na travessia adolescente.

[...] uma escola secundária deve conseguir mais do que não impelir seus alunos ao suicídio. Ela deve lhes dar o desejo de viver e devia oferecer-lhes apoio e amparo numa época da vida em que as condições de seu desenvolvimen- 
Os Cortes na Adolescência e a Busca por um Lugar na Cidade

to os compelem a afrouxar seus vínculos com a casa dos pais e com a família. Parece-me indiscutível que as escolas falham nisso, e a muitos respeitos deixam de cumprir seu dever de proporcionar um substituto para a família e de despertar o interesse pela vida do mundo exterior (Freud, 1970[1910], p. 218).

A partir destas palavras proferidas por Freud em uma escola após o suicídio de um de seus jovens alunos, consideramos que a adolescência só amplia e faz reverberar ainda mais a questão a respeito do lugar da escola na constituição dos circuitos do desejo. Portanto, a adolescência é um retorno que permite os rearranjos de relações antigas e a construção de novos e inéditos laços sociais. O adolescente busca um novo lugar no qual possa se ver digno de ser amado (Lecadée, 2011). Novos Outros que possam amá-lo mesmo quando a sua libido não se dirige mais (completamente) para os seus pais, já que o seu desejo é em grande parte endereçado para o campo social. Tudo isso constitui um campo para novas identificações e construção de um novo lugar/lugar possível para existir na cidade.

Assim, a psicanálise sublinha que a adolescência exige um trabalho psíquico de reinscrição do sujeito no laço social, o que implica novos modos de se representar como singular no coletivo, através de inovadoras e inéditas narrativas e novos endereçamentos discursivos. $\mathrm{O}$ adolescente tem como desafio ir além do lugar ocupado nos discursos familiar e no discurso social que possam levar ao silenciamento de seu desejo ou da sua dor (Coutinho, 2009, 2020). Entretanto, muitas vezes encontra impasses nesse percurso quando encontra como interlocutor o saber-todo presente em discursos familiares e/ou sociais que silenciam sua própria voz e dificultam sua possibilidade de reconhecer-se e autorizar-se em seu próprio ato. Nestes casos, muitas vezes prevalece um agir que expressa os embaraços do sujeito frente ao Outro (Jucá; Vorcaro, 1998; Lesourd, 2004), seja sob a forma de acting out seja sob a forma da passagem ao ato. Supomos que é no campo desse embaraço que podemos situar os dramas dos cortes na adolescência e vamos adensar esses argumentos através da discussão de um caso clínico.

\section{Dos Cortes às Insígnias: a construção de um novo laço ao Outro}

Propomos analisar o caso clínico de uma adolescente de quinze anos que chegou ao ambulatório através da indicação da escola em março de 2018. A escola percebeu que a adolescente se cortava no banheiro durante o turno escolar e, por isso, comunicou aos pais, sugerindo uma avaliação psiquiátrica no SPIA/IPUB-UFRJ. Desde então, a adolescente vem sendo atendida regularmente no serviço por uma psicóloga e por uma psiquiatra.

Quando Ingrid ${ }^{5}$ chega ao ambulatório, a mãe diz que soube que a filha se corta no banheiro da escola e não sabe dizer o motivo. Foi a diretora da escola quem entrou em contato com os pais para comunicar o que se passava. Para a mãe, a filha tem tudo e não deveria se cortar: 
lugar para morar, comida para comer e não lhe falta nada. Diz que acredita que os cortes não têm a ver com a sua vida e os atribui a uma tragédia recente que a família atravessou: o primo de Ingrid se suicidou com a arma do seu pai, que é policial aposentado. Sua mãe diz ainda que a psiquiatra do setor já havia medicado a filha, mas que não se lembra o nome do remédio.

A família, que mora em uma casa com dois cômodos, é composta por dez membros: mãe, pai, quatro filhas, neta, dois cachorros e um gato. A mãe de Ingrid me diz que está separada do pai das suas filhas, apesar de dividirem a casa. A mãe dorme com as filhas em um quarto, enquanto seu ex-marido dorme no outro sozinho. A mãe me diz ainda que o seu sonho sempre foi se tornar mãe e que investiu muito nas duas primeiras filhas, abrindo mão da sua vida para cuidar delas.

Porém, com a chegada das filhas na adolescência, relata que ficou muito decepcionada e frustrada, pois escutava das suas filhas o quanto ela era uma mãe ruim, a pior mãe do mundo e o quanto queriam que ela morresse. Isso fez com que se distanciasse, já que, segundo ela, parece que nenhuma delas se importa com ela e que nenhuma delas percebeu o quanto ela cuidou das filhas e não tem nenhum tipo de gratidão. A partir dessa experiência com as duas primeiras filhas, conta que, quando teve as duas mais novas, resolveu não passar tanto tempo com elas desde o nascimento, já que fariam exatamente como as irmãs mais velhas. Ingrid é a terceira filha desta mãe, que se mostra desacreditada e magoada com a duas primeiras filhas.

Já no primeiro contato com Ingrid, indagada sobre por que se cortava, ela diz que a vida é muito difícil e que os cortes ajudam a aliviar o que sente. Ingrid se diz muito negativa. Tentou se matar três vezes no último ano, mas não conseguiu, felizmente e infelizmente, em suas palavras. Na primeira tentativa, atravessou a rua na frente do carro e os seus amigos a puxaram. Diz ter sentido um misto de alegria e de tristeza: alegria, porque os amigos se importaram com ela e tristeza, porque continuaria a viver. Conta que não conseguiu se desculpar para os amigos pelo que fez e que se sentia culpada por isso. Diz fazer tudo sempre tão errado. Expressa que não saber fazer o certo. Quando indagada sobre o que faz de errado, diz novamente que é negativa.

Na segunda tentativa de suicídio, ingeriu uma grande quantidade de medicação, que não soube especificar a quantidade ou o nome. Mas que não adiantou, porque apenas dormiu por um longo período. Conta que ninguém percebeu que dormiu mais do que o normal, ninguém notou o que estava acontecendo. A terceira vez foi se cortando. Relata que pensava em se matar enquanto se cortava, mas sabia que não conseguiria. Diz que a escola percebeu o que estava acontecendo e comunicou aos pais que ela precisava de ajuda, o que foi recebido por ela como um alívio. Ao ser questionada sobre a medicação que estava tomando, Ingrid responde: citalopram - diferente da mãe, sabe exatamente o nome e o horário do remédio, se responsabilizando pelo seu uso.

Ao longo dos atendimentos, observamos o quanto o sofrimento da adolescente se associa à ausência de um olhar da mãe para a sua fi- 
Os Cortes na Adolescência e a Busca por um Lugar na Cidade

lha. Constatamos que a mãe não conseguia ver a sua filha em sua singularidade e separada das demais filhas condensando todas as quatro filhas em uma só, de modo que espera que todas reajam e se comportem da mesma maneira na adolescência: agressivas e ingratas em relação a ela. Com efeito, em conversas com a mãe paralelas ao atendimento de Ingrid, vimos que a mãe constantemente temia que Ingrid reagisse de forma violenta assim como as filhas mais velhas, o que impedia com que as duas construíssem uma relação singular.

Ingrid sofria muito, porque percebia que a mãe não a via diferente de suas irmãs e preocupava-se frequentemente em poupar a mãe de qualquer aborrecimento que pudesse vir a lhe causar. O lugar comum que lhe era destinado era o de uma adolescente que sentia dificuldade de aceitar o limite. A mãe não compreendia por que a adolescente se $r a-$ biscava como a sua neta rabiscava no papel, o que fazia com que a filha se sentisse cada vez mais sozinha e inaudível.

Quanto ao pai, quem por muitas vezes a trouxe para a terapia, Ingrid constantemente o caracterizava como incompreensivel e insensivel. A adolescente descreve algumas situações nas quais sentia que seu pai era egoísta e não a compreendia, tais como se deu ao comprar móveis para casa e, apesar de perguntar a sua opinião, escolher colocar os móveis no lugar onde ele própria pensava, o que fez Ingrid sentir que a sua opinião não valia nada. De modo semelhante, ela também se sentia bastante ofendida quando escutava o seu pai reclamar de que não gostava quando o seu namorado ia para a sua casa para, segundo ele, "comer a sua comida". Nesse sentido, parece que, em relação ao pai, prevalece o sentimento de não poder contar com ele, por estar envolvido em seus próprios problemas, incluindo-se aí a instabilidade na relação entre ele e a mãe, o que se faz notar quando ele deixa de ir ao aniversário de Ingrid por conta de um conflito entre o casal.

Apesar de a adolescente mencionar que tentou se suicidar através dos cortes, ela própria chega a mencionar que esses atos não visavam a sua morte, mas sim a uma busca por aliviar uma dor psíquica extremamente difícil de suportar, a saber: o fato de sentir que sua mãe não acreditava que ela era uma pessoa diferente das suas irmãs. Na ausência de um olhar para ela, Ingrid se sentia inexistente e o único recurso que conseguia usar era se cortar para que a dor física se sobrepusesse à dor psíquica e, com isso, reduzisse o que era da ordem do insuportável.

Essa atitude da paciente reitera a afirmação de Fortes (2012) de que a dor física vem muitas vezes substituir, ou tentar fazer desaparecer, a dor psíquica, evidenciando uma inegável dificuldade de elaboração psíquica de um evento doloroso. Ademais, os cortes autoinfligidos são realizados em momentos de uma insuportável tensão interna. Assim sendo, trata-se de uma dor que não encontra expressão pela via da palavra e/ou da elaboração psíquica e escoa para o corpo como o único recurso minimamente apaziguante, o que ecoa também com a posição sustentada por Le Breton (2006) e Araújo, Chatelard, Carvalho e Viana (2016), que compreendem a prática da autolesão como uma busca para se autopreservar e se autocurar. Portanto, no caso de Ingrid, a prática da autolesão nos parece muito mais uma forma da adolescente tentar se 
sentir viva, em busca de algo ou alguém que lhe ajude a suportar uma dor que não conseguia colocar em palavras. Como de fato, aconteceu.

Um aspecto importante a ser destacado no caso, para os fins da pesquisa, é o recurso aos cortes diante da vivência de não ter a quem endereçar o seu sofrimento. $\mathrm{O}$ ambiente familiar, frequentemente bélico e confuso, fazia a adolescente presenciar momentos de muitos conflitos, em que cada um preocupava-se com suas próprias questões e ninguém percebia o quanto ela estava sofrendo. Apesar de viver em uma casa com cinco pessoas, nenhuma delas pôde olhar para a adolescente e notar o tempo em que ficava trancada no banheiro ou as marcas em seus braços, por exemplo. Tampouco notaram seu olhar e seu tom de voz triste e melancólico. Assim, chama-nos a atenção ter sido no ambiente escolar que a adolescente foi vista pela primeira vez se cortando, apesar de ela expressar que é muito mais frequente se cortar no banheiro de casa do que da escola. Foi uma amiga de classe quem percebeu, inicialmente, os cortes do braço de Ingrid e, ao observá-los, comunicou a um dos coordenadores da escola o preocupante comportamento da amiga.

No atendimento de Ingrid, é importante notar a inclusão da escola na rede de cuidado da paciente. Em primeiro lugar, porque, quando ficou ciente dos cortes, a escola convocou os pais para conscientizá-los sobre o sofrimento da aluna e dirigir a eles a preocupação pelo cuidado da adolescente. Segundo, porque, como ficou claro na conversa da analista com um dos coordenadores por ocasião de uma visita à escola, havia lá um olhar para a adolescente que era capaz de estranhar alguns de seus comportamentos, como usar roupas de moletom em pleno verão quando o calor se fazia insuportável. Terceiro, porque, ao receber o pedido de aluna de mudança de turno no meio do período escolar, o diretor entrou em contato com a psicóloga para conversar sobre Ingrid e saber se estava frequentando o espaço do tratamento.

Observamos, portanto, que, no atendimento de adolescentes, a entrada da escola como parceira no tratamento é fundamental. No caso de Ingrid, a reivindicação de troca de turno pôde ser lida como mais um pedido de olhar e cuidado para si por parte da escola, o que, em sua família, parecia ser tão precário. A adolescente, ao se sentir perdida e sem lugar, fez um apelo à analista para que a ajudasse a fazer essa reinvindicação frente à escola. Pedido este já feito anteriormente à sua família, que não lhe respondeu. Neste endereçamento à analista, a adolescente, que se sentia sem lugar em casa e na escola, pede para que alguém a ajude a encontrar um lugar de acolhimento para o seu desejo. Por intermédio da analista, a escola pôde ouvir o sofrimento da aluna e o endereçamento de um pedido que pudesse ajudar a se sentir mais acolhida na escola e oferecer um espaço para troca de turno no ano seguinte. Assim, mesmo diante de inúmeros entraves e precariedades que marcam o funcionamento das escolas municipais do Rio de Janeiro, a mudança de turno foi efetivada.

É interessante notar como Ingrid inclui a escola e os seus pais em seu tratamento. Em um dado momento da terapia, a adolescente diz que não adianta ela se tratar e, seus pais, não. Estes, então, começaram 
Os Cortes na Adolescência e a Busca por um Lugar na Cidade

a vir semanalmente para conversar sobre a filha. No início usavam o espaço para falar de questões relacionadas ao casamento e todas as filhas. Inclusive com um pedido para que a psicóloga cuidasse de outra filha, já que Ingrid não queria mais ir. Conforme foram direcionados para falar apenas de Ingrid, começaram a perceber que este espaço era de Ingrid e não deles ou das outras filhas. Assim sendo, passaram a falar de como sua filha estava em casa, externavam preocupações e mesmo queixas de Ingrid.

Ingrid descreve, em inúmeras sessões, o quanto se sentia confusa e com dificuldade de lembrar-se o que se passava nas situações de intenso conflito familiar. Diz que é como se não estivesse presente. A adolescente descreve a sensação de ausência durante os conflitos, "como se estivesse neutra”, para não sentir nada durante as brigas da família. Para compreender este sentimento de ausência, recorremos a Le Breton (2006), que reconhece que a automutilação ${ }^{6}$ tem a finalidade de "[...] infligir-se um mal para se obter menos mal” (Le Breton, 2006, p. 5). Para um sujeito que se encontra em um estado de total vertigem e devastação psíquica, o corte reflete um modo de se infligir dor que visa à construção de um sentimento de existir de si próprio, segundo ele nitidamente ausente nestes casos. No caso de Ingrid, notamos o quanto a adolescente se sentia dentro de um ambiente vertiginoso que não ratificava a sua existência enquanto sujeito.

Ingrid dizia que, para se proteger, tentava se sentir neutra, isto é, tentava não se deixar afetar pelo que acontecia à sua volta com o objetivo de evitar entrar em contato com o ambiente familiar hostil e fonte de sofrimento. Tal como observam Fortes e Macedo (2017), dois fatores importantes podem ser observados nas autolesões entre adolescentes: se, por um lado, é frequente o relato de que não há com quem falar sobre a sua dor - pois não há a quem endereçar -, por outro lado, parece haver uma dificuldade do próprio sujeito em admitir a sua tristeza e o seu sofrimento. As autoras levantam a hipótese de que, diante de um outro indiferente, se produz a experiência da inexistência de si mesmo e a deserogeinização, o que, talvez, possa explicar a grande dificuldade de Ingrid em narrar e/ou lembrar das inúmeras situações familiares que a chatearam.

Portanto, se a capacidade de sentir e representar a própria dor tem relação com a possibilidade de que o sujeito entre em contato consigo mesmo, a presença do outro/Outro é igualmente fundamental para que o campo simbólico possa se instaurar psiquicamente como um recurso possível. Para que a dor psíquica possa ser endereçado a alguém, narrada e historicizada sob a forma de sofrimento, há de haver um espaço de ressonância que a legitime (Birman, 2012; Fortes; Macedo, 2017), e foi isso que observamos no andamento dos atendimentos com Ingrid. Na medida em que a adolescente encontra um espaço de cuidado nos atendimentos, sua angústia pode, muito lentamente, encontrar palavras para se fazer representar. Os cortes rasgam a pele para o sangue arrefecer a dor psíquica, mas, a cada sessão em que as palavras ganham espaço, torna-se possível fazer um corte no circuito pulsional mortífero vigente até então. Assim, assistimos Ingrid transformar a dor em sofri- 
mento, na medida em que encontra alguém a quem possa endereçar o que sente. A dor como uma descarga direta no corpo encontra um espaço de ressonância, isto é, alguém que não apenas escute, mas também que devolva o que escuta sob forma de acolhimento.

No caso de Ingrid, o percurso da dor ao sofrimento aparece de forma muito expressiva, na medida em que a adolescente colocou em seus pingentes do colar que usava para vir às sessões as marcas de transformação de sua posição subjetiva frente ao Outro. Ao substituir o pingente da baleia por um em forma de gilete, a adolescente coloca pendurado em seu pescoço um objeto que antes era usado para se cortar e que, agora, passa a ser pendurado e oferecido ao olhar da analista, dando um outro destino a esse objeto tão importante na sua trajetória de vida. Posteriormente, troca o pingente da gilete pelo da tesoura, quando decide cortar seus cabelos ao invés de cortar a sua pele. Contemplamos aqui mais uma virada na vida da adolescente, que decide romper com as expectativas da mãe em relação a ela, e vice-versa, para sustentar o seu próprio desejo e cuidar de si. Desta forma, se tranca no banheiro de casa, como muitas vezes já fizera antes, mas não para cortar a sua pele, e sim o seu cabelo numa tentativa de se separar, enquanto sujeito desejante, de sua mãe.

Assim, uma narrativa sobre os cortes pode ser construída e a moça começa a caminhar em direção à busca de um lugar próprio na família e na cidade. Decide fazer um programa para comemorar o seu aniversário e lá começa a namorar um rapaz, com quem sai para passear pela cidade de bicicleta. Aceita o convite para ir conhecer seus familiares e passa a frequentar regularmente espaços públicos com o namorado e a família dele. Paralelamente, expressa o seu desejo de trabalhar e morar sozinha com o intuito de ter o seu próprio espaço e sair da confusão que era a sua casa. Para isso, estava sempre pensando em tirar a sua carteira de trabalho, e pediu algumas vezes para a sua mãe acompanhá-la, mas diz que a mãe nunca pôde porque estava sempre ocupada com o seu próprio trabalho ou com as tarefas domésticas. Muitas vezes compartilhou nas sessões sua frustração em não saber como tirar a sua carteira de trabalho e, diante do acolhimento da analista para conversar sobre isso, pôde buscar na internet, por si própria, informações sobre como proceder. Inicialmente, Ingrid queria trabalhar no programa de Jovem Aprendiz, mas conseguiu um emprego na empresa do pai de um amigo. Diz, porém, que, apesar de gostar do trabalho, não queria ficar ali por muito tempo, porque queria ganhar mais dinheiro para alugar a sua própria casa e fazer as suas coisas.

Ainda que frente à falta de perspectiva familiar, supomos que a escuta da analista e o acolhimento da escola permitiram que a jovem criasse meios de circular pela cidade de forma inédita e construir novos enlaçamentos discursivos, podendo se sentir existir, se ver e se dizer de forma própria. A partir do atendimento de Ingrid, pudemos pensar que oferecer um espaço de escuta é fornecer um lugar onde seja possível construir uma narrativa acerca do que aparece no corpo em forma de corte. É ofertar um lugar no qual a dor possa ser legitimada, endereçada 
Os Cortes na Adolescência e a Busca por um Lugar na Cidade

e transmutada. É transformar o inenarrável em palavras, frases e texto a ser compartilhado.

\section{Em Tempos de Vazio e de Excesso: o corte como resposta?}

Segundo dados do Ministério da Saúde, cerca de 20\% dos jovens brasileiros estão se autolesionando, o que representa 14 milhões de pessoas ${ }^{7}$. Além disso, tais práticas, que costumam surgir na adolescência e podem se estender até a fase adulta do sujeito, tiveram um aumento considerável nos últimos 30 anos. Por isso, a urgência de se olhar para esse fenômeno mais detidamente e compreender o que este ato dramático diz acerca da nossa sociedade atual.

Alguns psicanalistas têm se dedicado a pensar sobre os atos de autolesão como uma das expressões do mal-estar contemporâneo, que se dá sobretudo através da realização de escarificações e cortes na superfície corporal da pele (Jucá; Vorcaro, 1998; Fortes; Macedo, 2017, Araújo; Chatelard; Carvalho; Viana, 2016; Monster, 2012; Le Breton, 2006). De fato, este fenômeno tem ganhado muita visibilidade na clínica psicanalítica nas últimas décadas e o ambulatório público torna-se um espaço importante como observatório deste mal-estar. Nas observações realizadas por alguns desses autores, constata-se que não há uma relação necessária entre os cortes e o suicídio. Os cortes autoinfligidos envolvem uma relação entre o próprio corpo e a forma de expressão do sofrimento psíquico sem a intenção de se matar, ao contrário do que uma leitura leiga e superficial poderia indicar. Outro fato observado é que o adolescente não demonstra inquietação ou preocupação com o fato de se autolesionar. $\mathrm{O}$ alarme é acionado apenas quando o adulto descobre e se preocupa com o fato. Além disso, observa-se a ausência de referência à dor no momento do corte. Como já foi dito, ao invés de dor física, o relato é de grande alívio, ressaltando-se o caráter apaziguante do ato.

Como temos observado em diversos casos atendidos no âmbito da pesquisa, e não é diferente no caso de Ingrid, os cortes autoinfligidos são realizados pelos adolescentes em momentos de uma insuportável tensão interna que não sabem como lidar. Trata-se de uma angústia que não encontra expressão pela via da palavra e escoa para o corpo, encenando um transbordamento dos limites psíquicos, que nos remete à angústia automática descrita por Freud (1974 [1926]) em sua segunda teoria da angústia, articulada com a dimensão do traumático e do desamparo. Trata-se, como então descreve, da experiência relacionada à ausência ou falta de amparo referida à primeira experiência de absoluta dependência e submissão do bebê que, por sua imaturidade orgânica e psíquica, é inteiramente dependente dos cuidados de outrem e incapaz de sobreviver sozinho. Portanto, retomando brevemente Freud em 1926, enquanto a angústia sinal presente na formação do sintoma neurótico implica no recalque, no esquecimento e em marcas psíquicas de uma situação vivida de desprazer, a angústia automática invade o eu e o fragiliza, já que fica submetido ao id. Nesse caso, o eu, rendido a sua posição de objeto, sem recursos para ligar as intensidades, repete a experiếncia inaugural de desamparo de onde adveio ${ }^{8}$. 
Quando seguimos a linha de construção da teoria pulsional freudiana para compreender os cortes autoinfligidos como descarga da pulsão direta no corpo, somos levados à concepção freudiana desenvolvida em 1895 em seu texto Projeto para uma Psicologia Científica (Freud, 1974 [1895]), onde Freud apresenta a fundamental necessidade da presença do outro no processo de constituição do sujeito frente ao desamparo inerente à condição humana. A partir desse pressuposto, é na alternância dos movimentos de ausência e presença do outro primordial que se instauram recursos para enfrentar e metabolizar a dor.

Pontalis (2005) afirma que a dor acontece quando não há suporte ou quando não há mediação possível. A dor surge quando se rompem os dispositivos de proteção do psiquismo e quando o "[...] cheio demais cria o vazio" em virtude do curto-circuito que se dá dentro do aparelho psíquico (p. 268). O efeito é, portanto, de uma implosão psíquica, cuja consequência é a ruptura de proteção, gerando uma descarga não simbolizada no próprio corpo. A dor se torna, então, irredutível. Ainda para Pontalis (2005), a dor, por não ser comunicável, por ser só para si, só tem a possibilidade de expressão por meio de uma alternância entre grito e silêncio. O sujeito, ele próprio, não se comunica com a sua dor, mas, a partir dela, alterna posições entre o silenciamento e o grito. Nessa alternância entre grito e silêncio, a autolesão pode ser também concebida como uma dor silenciosa (Gauthier, 2007).

A prática de se autolesionar como forma de aliviar a angústia irrepresentável provocando em si mesmo a dor, ardência ou uma sensação física na pele tem sido pensada como um fenômeno de borda, que remete à fronteira entre o psíquico e o somático, e, portanto, aos impasses na inscrição psíquica da pulsão (Costa, 2003). Tais práticas podem ser tomadas, eventualmente, como repetições na tentativa de inscrever psiquicamente o Outro, em analogia à lógica do traumático para a psicanálise. Portanto, nesse trabalho psíquico do excesso pulsional, que é sempre tão caro ao adolescente no momento de queda das referências parentais da infância, o eixo alteritário, o lugar do Outro na cultura, é inevitavelmente convocado, já que "[...] as bordas corporais são, por princípio, 'bordas sociais', tendo em vista que são efeitos de nossa relação á linguagem - lugar desse Outro primordial - que é, desde o início, produtora de laço social" (Costa, 2003, p. 23).

O quadro clínico da autolesão encena questões fundamentais para a análise dos laços alteritários e suas repercussões no mal-estar da atualidade, mais especificamente, relacionados à adolescência. Monster (2012) define a dor corporal como um substituto da dor moral. A dor no corpo, os cortes, afirmam a impossibilidade de sentir a dor da alma. Já Le Breton (2006) assevera que a autolesão ilustra um jogo simbólico de domínio da dor, na medida em que opõe dor ao sofrimento e ferida física ao dilaceramento da alma. Em seus estudos com adolescentes, atesta que, ao se infligirem dor física, os adolescentes buscam retomar o controle de um afeto que, se sentido, se torna destrutivo. Os cortes se constituem como um modo de domínio de uma situação que escapa totalmente ao seu controle. Nas palavras de Le Breton (2006, p. 02), esse sentimento é uma "[...] forma de hemorragia de sofrimento que destrói 
Os Cortes na Adolescência e a Busca por um Lugar na Cidade

os limites de si". Surpreendentemente, os cortes que rasgam a pele constroem limites para o sofrimento, como uma tentativa de contê-lo. Com efeito, os cortes vêm como uma tentativa de conferir uma restauração brutal das fronteiras perdidas do corpo para diminuir o sentimento de vertigem e promover uma sensação de vida. A sensação de vertigem reflete a impossibilidade de domínio da enorme intensidade experimentada pelo psiquismo e os cortes são uma tentativa de alguma ligação possível frente ao desespero experimentado. Isto é, uma forma de esboçar uma resposta ali justamente onde o chamado ao Outro não encontra resposta.

Portanto, para o autor, o alvo do corte não é o sofrimento, mas, paradoxalmente, uma forma de alcançar certo sentimento de existir. A autolesão parece ser uma forma de se sentir (viva) e sair da permanente sensação de perda de si e de anestesiamento. Sentir a dor parece ser um recurso cuja finalidade é suspender a sensação de amortecimento e a sensação de estar morto(a). A cinestesia provocada pelos cortes pode trazer a sensação e a intensidade perdidas, de modo a transformar a matéria bruta do corpo em carne viva (Le Breton, 2006). A sensação de vertigem que domina o sujeito provoca uma sensação de estar morto em vida, como um morto-vivo. Por isso, se cortar é tentar viver e não morrer. Observamos, porém, que a autolesão reflete um importante fracasso da palavra em seu potencial de conexão simbólica e inserção no laço social.

\section{O Esfumaçamento do Outro e seus Efeitos na Adolescência: uma questão clínicopolítica}

Um dos aspectos destacados no caso de Ingrid é o sentimento de solidão e de inexistência de um interlocutor com quem possa compartilhar a sua dor. Outro fato observado no caso é o caráter compulsivo dos cortes autoinfligidos e que tem ressonância no relato de muitas adolescentes nas redes sociais que se diziam viciadas a tal ponto de não conseguirem parar de se cortar (Fortes; Macedo, 2017). O vício nos cortes reflete o parentesco desses atos com o gozo das compulsões e com a falência de recursos simbólicos para colocar a dor em palavras. A falta de um interlocutor com quem possa compartilhar a sua dor e o seu e malestar reflete um modo de sofrer que se configura como uma descarga direta de uma intensidade pulsional na dimensão da sensação corporal.

O esfumaçamento da dimensão subjetiva da alteridade se revela como fato marcante não apenas na produção do quadro de autolesão, mas como eixo fundamental para pensar a presença das questões sociopolíticas na constituição do mal-estar contemporâneo, como desenvolve Birman (1999, 2012). Segundo o autor, fatores contemporâneos como o excesso de estímulo ao narcisismo e o arrefecimento da relação com o outro ${ }^{9}$ desenham um pano de fundo sobre o qual se apresentam quadros psicossomáticos, compulsões e diversos tipos de atuações.

Qual seria, então, a relação deste traço de esfumaçamento do Outro no contemporâneo com um modo de sofrer que se desenha sobre o 
espaço corpóreo? Dois fatores importantes podem ser observados. Se, por um lado, não há a possibilidade de um endereçamento, que implicaria na referência a um outro para receber a mensagem da dor, por outro lado, parece haver uma dificuldade do próprio sujeito em reconhecer a sua tristeza, o seu sofrimento. Nesse sentido, Birman $(1999,2012)$ sublinha que a capacidade de representar e nomear a própria dor tem como condição a presença de um interlocutor, a possibilidade compartilhar 0 vivido para que esse se transforme em experiência. Tal como no masoquismo primário, articulado ao desamparo, nessa posição, o sujeito faria um apelo ao outro para transformar a dor em sofrimento. Portanto, a inscrição do outro no psiquismo é simultânea à possibilidade do próprio eu se fazer sofrer ativamente na fantasia. A partir dessa premissa, o autor faz uma distinção entre dor e sofrimento (Birman, 2012). A dor caracteriza-se pela ausência de mediação do outro e o sujeito fica entregue ao excesso pulsional que o acossa. Com isso, a pulsão retorna para si, expressando a impossibilidade de enunciação da intensidade. No sofrimento, por outro lado, há a presença de um outro que pode oferecer a função de um anteparo contra esse excesso pulsional que invade o sujeito e permite a construção de uma narrativa sobre a dor, transformando-a em sofrimento passível de ser partilhado e historicizado.

Nesse sentido, o ato contra si próprio é uma denúncia da rasura dos investimentos psíquicos do outro, o que se vê nos casos de autolesão. Na ausência de um outro como testemunha, esta dor, ao invés de poder ser partilhada e temporalizada, mantém-se no campo do espaço, atrelada ao próprio corpo, não é transformada em sofrimento. A partir dessa distinção, é possível distinguir, também a partir de Birman (2012), dois modos de sofrer no contemporâneo que podem nos ajudar a pensar nesses casos: o desamparo e o desalento. Na perspectiva do desamparo, que remete ao estado psíquico inaugural do sujeito humano ligado à condição de dependência originária, faz sentido o apelo ao outro, já que a alteridade está presente no campo psíquico. Já a experiência de desalento, marcada pela dor, fala de um grau a mais no desamparo, na medida em que lança o sujeito no abismo do solipsismo, da solidão e do vazio, com ausência de interlocução, ou seja, com a subtração de possibilidade de se fazer apelo ao outro. O sujeito vive, neste cenário, dentro da lógica da desesperança.

A presença do desamparo e do desalento na clínica atual, não somente nos casos de autolesão, pode ser pensada a partir de mudanças na esfera da cultura e do funcionamento social. A hegemonia dos paradigmas medicalizante e naturalizante, bastante presentes no campo educativo de modo amplo, atua na contramão das possibilidades de subjetivação da dor. Podemos também atrelar a isso, as incidências do capitalismo avançado atreladas a esses discursos no sujeito, produzindo o esvaziamento do sentido da vida - que tende a ser reduzida a sua dimensão biológica; a relativização da existência compartilhada e a fragilização da experiência que torna possível a historicização do sujeito, como apontam Rosa, Vicentin e Catroli (2009). Com isso, a presença de discursos que empurram o sujeito ao gozo, seja sob a forma do consumo seja sob a forma de determinados modos de sofrer, desestabiliza 
Os Cortes na Adolescência e a Busca por um Lugar na Cidade

os laços sociais. A lógica do capital leva a destituição do outro e à corrosão das bases simbólicas da convivência, evidenciando a dimensão sociopolítica (Rosa, 2016) do sofrimento juvenil. Por isso, é importante para as instituições que trabalham com adolescentes pensar formas de reinstaurar outras discursividades possíveis que não aquelas que calam o sujeito normatizando-o (Rosa; Vicentin, 2013), mas sim que possibilitem acolher as singularidades e o sofrimento dos sujeitos que dela tomam parte.

No campo da educação especificamente, podemos escutar, a partir do caso discutido, um apelo para que a escola possa participar mais efetivamente da travessia adolescente, através de um olhar para os sujeitos que por ela passam. Um apelo, podemos dizer, por políticas educativas mais afeitas às relações humanas e ao trabalho do educador, e não por projetos que preconizem a técnica e o produtivismo em detrimento das vidas e da dimensão da experiência compartilhada no espaço escolar. Entretanto, sabemos que tais instituições são atravessadas pelas tensões e disputas em torno dos saberes e dos poderes que se apresentam em um dado tempo e lugar. O que nos leva a questionar sobre qual a relação entre o modelo político neoliberal, com o acirramento do individualismo em várias esferas sociais, e, no caso do Brasil, com o declínio acentuado do espaço público já sempre tão precário, e a tão grande incidência de atos autolesivos e de suicídios entre os jovens nos últimos anos? Não é difícil pensar que a omissão do estado diante dos altos índices de evasão escolar no ensino médio e de sofrimento psíquico de alunos e professores da rede pública se coaduna com a necropolítica $^{10}$ (Mbembe, 2018) instaurada no estado brasileiro nos últimos anos. Ou ainda, no para além da necropolítica, como observa Safatle (2020) a partir da noção de estado suicidário, as modificações paradigmáticas no exercício do poder visando a uma adaptação aos processos do neoliberalismo incluem uma consolidação da indiferença e da desafecção como afeto social fundamental.

A partir da distinção entre desalento e desamparo, é possível supor que a passagem de um modo de funcionar ao outro dependa da crença na existência de instâncias sociais de apelo, sustentadas por um amparo político e institucional. Bem como da possibilidade de os adolescentes serem incluídos no discurso social como sujeitos, portadores de suas próprias histórias, de possibilidades de se narrar e de ocupar seu lugar na polis. A condição precária do Outro, seja na família, seja nas esferas educativas ou no campo social mais amplo, produz impasses em colocar a dor em palavras e endereçá-la, subjetivando-a e politizando-a.

Gostaríamos de finalizar chamando a atenção para o fato de que a autolesão nem sempre pode ser atrelada a uma tentativa de suicídio, e, tanto uma quanto a outra precisam ser pensadas no singular de cada caso, mas ambas podem ser vistas, em muitos casos, como tentativas de fazer borda, que não deixam de fazer sempre um apelo ao Outro. Se a adolescência reedita o necessário suporte no Outro para a erotização e os enlaçamentos com a vida, é importante reafirmar que isso se dá mais para além da esfera da família, convocando os vários discursos e 
instituições que compõem a cidade. Nesse sentido, o tratamento para esse mal-estar, tomado em sua dimensão sociopolítica, envolve várias instâncias e diz respeito tanto ao campo da clínica quanto às esferas da educação e da política.

Recebido em 12 de novembro de 2020 Aprovado em 24 de fevereiro de 2021

\section{Notas}

1 A Organização Mundial de Saúde (OMS) inclui a autolesão no contexto da violência autoinfligida, correspondendo ao uso intencional de força física real ou de ameaça contra si próprio (Organização Mundial de Saúde, 2014a). Os tipos de violência autoinfligida são: tentativas de suicídio, suicídio, autoflagelação, autopunição e autolesão (Brasil, 2016). Enquanto a OMS aponta o suicídio como a segunda maior causa de morte entre jovens de 15 a 29 anos em todo o mundo (Organização Mundial da Saúde, 2014b), segundo dados do Ministério da Saúde, o suicídio representa a quarta maior causa de mortes entre jovens da mesma faixa etária (Brasil, 2016). Em termos mundiais, constata-se que cerca de dez por cento dos adolescentes entre 10 e 14 anos praticam a autolesão, mas não há dados suficientes sobre isso especificamente no Brasil (Fonseca et al, 2019).

2 Tomamos a adolescência como o trabalho psíquico imposto aos jovens pelas mudanças sociais que caracterizam a Modernidade, conforme sustentamos anteriormente (Coutinho, 2009). Dessa forma, adotaremos os termos adolescência e adolescentes quando ressaltarmos as operações psíquicas a eles vinculadas, enquanto os termos juventude e jovem serão preferencialmente utilizados quando nos referirmos à classe social, mais destacada pelo olhar sociológico.

3 O artigo é proveniente de uma pesquisa em andamento no Programa de PósGraduação em Psicologia da UFF em parceria com o SPIA/ IPUB-UFRJ intitulada Educação para a vida: suicídios na adolescência e vulnerabilidades sociais.

4 A pesquisa foi aprovada pelo comitê de ética em pesquisa sob o CAAE $\mathrm{n}^{\circ}$ 20131119.6.0000.8160.

5 O nome da paciente foi substituído por um fictício de modo a manter o sigilo do caso clínico.

6 Optou-se aqui por manter o termo automutilação conforme utilizado pelo autor no original consultado.

7 Ministério lança vídeo em alerta à disseminação de conteúdo sobre suicídio e automutilação. Junho de 2019. Disponível em: <https://www.gov.br/mdh/ pt-br/assuntos/noticias/2019/junho/ministerio-lanca-video-em-alerta-adisseminacao-de-conteudo-sobre-suicidio-e-automutilacao>.

8 Importante notar aqui que, a partir do que aponta Freud em Inibições, Sintoma e Angústia (1976[1926]), nesse regime de funcionamento psíquico, não há sintoma, há clivagem do eu e atuações (acting out ou passagem ao ato) dentre as quais podemos enquadrar as autolesões, respeitando-se as especificidades de cada caso. Mas não poderemos desenvolver mais esses argumentos no escopo deste artigo.

9 Utilizamos aqui outro em minúscula quando fazemos referência à produção de Birman (1999, 2012), sem fazer distinção em relação ao Outro com maiúscula 
Os Cortes na Adolescência e a Busca por um Lugar na Cidade

definido por Lacan, já que o autor atém-se prioritariamente ao referencial freudiano em suas formulações. No restante do texto, quando adotamos o termo Outro com maiúscula, fazemos referência ao grande Outro enquanto instância simbólica teorizada por Lacan diante da qual se constitui o sujeito e que distingue-se do pequeno outro enquanto o semelhante, imaginário e passível de ser encarnado nas relações sociais (Lacan, 1998a [1949]; 1985 [1954$55])$.

10 Enquanto o biopoder na teoria foucaultiana refere-se ao exercício do poder sobre a vida, a necropolítica é a expressão cunhada por Mbembe (2018) quando a política tem o domínio sobre a morte, o assassinato do inimigo como seu objetivo primeiro e absoluto.

\section{Referências}

ALBERTI, Sonia. O Adolescente e o Outro. Rio de Janeiro: Zahar, 2004.

ALBERTI, Sonia; ELIA, Luciano. Psicanálise e Ciência: o encontro dos discursos. Mal-Estar e Subjetividade, Fortaleza, v. 8, n. 3, p. 779-802, 2008. Disponível em: <http://pepsic.bvsalud.org/pdf/malestar/v8n3/10.pdf >. Acesso em: 11 out. 2020.

ARAÚJO, Juliana; CHATELARD, Daniela; CARVALHO, Isalena; VIANA, Terezinha. O Corpo na Dor: automutilação, masoquismo e pulsão. Estilos da Clínica, São Paulo, v. 21, n. 2, p. 497-515, 2016.

BRASIL. Ministério da Saúde. Suicídio. Saber, Agir, Prevenir. Boletim epidemiológico. Brasília, v. 48, n. 30, 2016.

BRUM, Eliane. Uma Duas. São Paulo: Leya, 2011.

BIRMAN, Joel. O Espetáculo e o Narcisismo. In: BIRMAN, Joel. Mal-Estar na Atualidade. Rio de Janeiro: Civilização Brasileira, 1999. P. 85-87.

BIRMAN, Joel. O Sujeito na Contemporaneidade. Rio de Janeiro: Civilização Brasileira, 2012.

COSTA, Ana. Tatuagens e Marcas Corporais. São Paulo: Casa do Psicólogo, 2003.

COUTINHO, Luciana Gageiro. Adolescência e Errância: destinos do laço social contemporâneo. Rio de Janeiro: Editora Nau, 2009.

COUTINHO, Luciana Gageiro. O Adolescente e a Educação no Contemporâneo: o que a psicanálise tem a dizer. Cadernos de Psicanálise-CPRJ, Rio de Janeiro, v. 37, n. 33, p. 155-174, jul./dez. 2015.

COUTINHO, Luciana Gageiro. Mal-Estar na Escola: o discurso dos professores diante dos imperativos educativos contemporâneos. Educação Temática Digital. Campinas, v. 21, n. 2 p. 348-362, abr./jun. 2019.

COUTINHO, Luciana Gageiro. Ocupa Escola: tratamento aos impasses da adolescência no laço social?. Estilos Da Clínica, Rio de Janeiro, v. 25, n. 1, p. 63-76, 2020.

FONSECA, Paulo Henrique Nogueira da et al. Autolesão Sem Intenção Suicida entre Adolescentes. Arquivos Brasileiros de Psicologia, Rio de Janeiro, v. 70, n. 3, p. 246-258, 2018.

FORTES, Isabel. A Dor Psíquica. Rio de Janeiro: Cia. de Freud, 2012.

FORTES, Isabel; MACEDO, Monica. Automutilação na Adolescência. Psicogente, v. 20, n. 38, p. 353-367, 2017. 
FREUD, Sigmund. Contribuições para uma discussão acerca do suicídio. In: Obras Psicológicas Completas da Standard Edition. Rio de Janeiro: Imago. Vol. XII. 1970. P. 25-66. [1910]

FREUD, Sigmund. Três Ensaios sobre a Teoria da Sexualidade. In: FREUD, Sigmund. Obras Psicológicas Completas da Standard Edition. Rio de Janeiro: Imago. Vol. VII. 1972. P. 135-237. [1905]

FREUD, Sigmund. Projeto para uma Psicologia Científica. In: FREUD, Sigmund. Obras Psicológicas Completas da Standard Edition. Rio de Janeiro: Imago. Vol. I. 1974. P. 335-454. [1895]

FREUD, Sigmund. Inibições, sintomas e ansiedade. In: FREUD, Sigmund. Obras psicológicas completas da Standard Edition. Rio de Janeiro: Imago, vol. XX, 1976. [1926]

FREUD, Sigmund. Introdução ao Narcisismo. In: FREUD, Sigmund. Obras psicológicas completas da Standard Edition. Rio de Janeiro: Imago, vol. XIV, 1996. P. 81-110. [1914]

GAUTHIER, Martin. Automutilation et Autoérotisme. Topique, v. 99, n. 2, p. 5159, 2007.

IRIBARRY, Isac Nikos. O Que É Pesquisa Psicanalítica? Ágora, v. VI, n. 1, p. 115138, 2003.

JUCÁ, Vládia Santos; VORCARO, Angela Maria Resende. Adolescência em Atos e Adolescentes em Ato na Clínica Psicanalítica. Revista Psicologia-USP, São Paulo, v. 29, n. 2, p. 246-252, 1998.

JULIEN, Philipe. Abandonarás teu Pai e tua Mãe. Rio de Janeiro, Companhia de Freud, 2000.

LACAN, Jacques. O Seminário, Livro 2: o eu na teoria de Freud e na técnica da psicanálise. Rio de Janeiro: Jorge Zahar, 1985. [1954-55]

LACAN, Jacques. O Seminário, Livro 11: os quatro conceitos fundamentais da psicanálise. Rio de Janeiro: Jorge Zahar, 1990. [1964]

LACAN, Jacques. O Estádio do Espelho como Formador da Função do Eu Tal como Nos É Revelada na Experiência Psicanalítica. In: LACAN, Jacques. Escritos. Tradução de Vera Ribeiro. Rio de Janeiro: Jorge Zahar Editor, 1998a. P. 96103. [1949]

LACAN, Jacques. Kant com Sade. In: LACAN, Jacques. Escritos. Tradução de Vera Ribeiro. Rio de Janeiro: Jorge Zahar Editor, 1998b. P. 776-806. [1963]

LACAN, Jacques. O Seminário, Livro 5: as formações do inconsciente. Rio de Janeiro: Jorge Zahar, 1999. [1957-58]

LACADÉE, Philippe. O Despertar e o Exílio: ensinamentos psicanalíticos da mais delicada das transições, a adolescência. Rio de Janeiro: Contra Capa Livraria, 2011.

LE BRETON, David. Scarifications Adolescentes. Enfances \& Psy, v. 3, n. 32, p. $45-57,2006$

LESOURD, Serge. A Construção Adolescente no Laço Social. Petrópolis, RJ: Vozes, 2004.

MONSTER, Little. Mon Combat Au Quotidien: l'automutilation [arquivo de vídeo], 2012. Disponível em: <http://youvideoz.com/watch?v=ahW_RnRaSH0>. Acesso em: 19 ago. 2020.

MBEMBE, Achille. Necropolítica. São Paulo, SP: n-1 edições, 2018. 
Os Cortes na Adolescência e a Busca por um Lugar na Cidade

ORGANIZAÇÃO MUNDIAL DE SAÚDE. Relatório Mundial Sobre a Prevenção da Violência. São Paulo: Fapesp, 2014a.

ORGANIZAÇÃO MUNDIAL DA SAÚDE. Preventing Suicide: a global imperative. Genebra, 2014b.

POLI, Maria Cristina. Escrevendo a Psicanálise em uma Prática de Pesquisa. Estilos da Clínica, São Paulo, v. Xlll, n. 25, p. 154-179, dez. 2008.

PONTALIS, Jean Bertrand. Entre o Sonho e a Dor. São Paulo: Ideias e Letras, 2005.

ROSA, Miriam Debieux, VINCENTIN, Maria Cristina; CATROLI, Viviani. Viver em Tempos Sombrios: a experiência e os laços com os contemporâneos. Psicologia em Revista, Belo Horizonte, v. 15, n. 1, p. 51-68, abr. 2009.

ROSA, Miriam Debieux; VICENTIN, Maria Cristina. Os Intratatáveis: o exílio dos adolescentes do laço social pelas noções de periculosidade e irrecuperabilidade. In: GURSKI, Rose; ROSA, Miriam Debieux; POLI, Maria Cristina (Org.) Debates Sobre a Adolescência Contemporânea e o Laço Social. São Paulo: Juruá, 2013. P. 39-58.

ROSA, Miriam Debieux. A Clínica Psicanalítica em Face da Dimensão Sociopolítica do Sofrimento. São Paulo: Escuta, 2016.

SAFATLE, Vladimir. Para Além da Necropolítica. Pandemia Crítica. N1 Edições, Rio de Janeiro: 2020.

SANTOS, Eliane Gomes; SALADA, Mari Gloria Schwab. Alteridade e Adolescência: uma contribuição da psicanálise para a educação. Educação \& Realidade, Porto Alegre, v. 38, n. 2, p. 555-568, abr./jun. 2013.

ZELMANOVICH, Perla. A Equação Família-Escola: entre o reenvio da importância e a dialética alienação e separação. In: VOLTOLINI, Rinaldo (Org.). Retratos do Mal-Estar Contemporâneo na Educação. São Paulo: Escuta/Fapesp, 2014. P. 236.

Luciana Coutinho é psicanalista, Psicóloga, Doutora em Psicologia pela PUC-Rio e Professora Associada da Faculdade de Educação da Universidade Federal Fluminense. Membro dos PPG em Educação e PPG em Psicologia/UFF. Membro do NIPIAC/UFRJ e coordenadora do LAPSE/UFF.

ORCID: http://orcid.org/0000-0001-5535-5931

E-mail: lugageiro@uol.com.br

Bruna Madureira é psicóloga, Doutora em Psicologia pela PUC-Rio. Especialista em Psiquiatria e Psicanálise com Crianças e Adolescentes pelo SPIA/IPUB-UFRJ. Especialista em Saúde Mental de Crianças e Adolescentes pelo APIA/IPUB-UFRJ. Pesquisadora do LIPIS/PUC-Rio e do LAPSE/UFF. ORCID: http://orcid.org/0000-0002-8475-7670

E-mail: bruna.madureira@hotmail.fr

Editora-Responsável: Fabiana de Amorim Marcello

Este é um artigo de acesso aberto distribuído sob os termos de uma Licença Creative Commons Atribuição 4.0 Internacional. Disponível em: <http:// creativecommons.org/licenses/by/4.0>. 